\title{
Basics of research (Part 13): Qualitative research-an example
}

Cheryl Thompson

University of Nebraska Medical Center, cbthompson@unmc.edu

Edward A. Panacek

University of California, Davis

Tell us how you used this information in this short survey.

Follow this and additional works at: https://digitalcommons.unmc.edu/con_articles

Part of the Nursing Commons

\section{Recommended Citation}

Thompson, Cheryl and Panacek, Edward A., "Basics of research (Part 13): Qualitative research--an example" (1998). Journal Articles: College of Nursing. 23.

https://digitalcommons.unmc.edu/con_articles/23

This Article is brought to you for free and open access by the College of Nursing at DigitalCommons@UNMC. It has been accepted for inclusion in Journal Articles: College of Nursing by an authorized administrator of DigitalCommons@UNMC. For more information, please contact digitalcommons@unmc.edu. 


\title{
Basics of Research (Part 13): Qualitative Research-An Example
}

\author{
Cheryl Bagley Thompson, PhD, RN,' and Edward A. Panacek, MD²
}

1. University of Utah College of Nursing, Salt Lake City

2. University of California-Davis Medical Center, Sacramento

Address for correspondence and reprints: Cheryl Bagley Thompson, PhD, RN, University of Utah College of Nursing, $10 \mathrm{~S}$. 2000 E. Front St., Salt Lake City, UT 84112

Key Words: nursing research, qualitative research

Copyright @ 1998 by the Air Medical Journal Associates

$1067-991 \times / 98 / \$ 5.00+0$

Reprint no. 74/1/92482

\section{Introduction}

In the previous installment of the "Basics of Research" series, ${ }^{1}$ the topic of qualitative research was introduced. Part 12 discussed the process and specific types of qualitative research and research questions for which the method would be appropriate. The purpose of this installment is to further clarify concepts related to qualitative research and use these concepts to present a detailed description of a hypothetical qualitative study.

Qualitative research refers to studies that "examine events or experiences in context from the perspective of the individuals experiencing the phenomena." ${ }^{1}$ The term qualitative is used to describe the type of data collected, a group of methods, a philosophy, and a method of data analysis. ${ }^{2,3}$ Researchers like Madeleine Leininger and Jean Watson are identified as qualitative researchers, and Cheryl Erler and Norm Snow are recognized for their quantitative research. Investigators first should identify the research question and then select an appropriate method for answering that question. $^{3}$

Deciding which method to use for a particular research question may be hindered by inconsistencies in the literature regarding the terms qualitative and quantitative. For example, one researcher may refer to a study that uses a questionnaire with open-ended questions as quantitative, whereas another may use several open-ended questions as part of a qualitative study. ${ }^{3}$ Other readers may wonder what the true difference is between a study that is purely descriptive (pre- or nonexperimental) and a study using grounded theory to describe a process.

In the two cases above, much of the difference lies in the philosophy of the researcher and the purpose of the study. Qualitative studies tend to be aimed at creating a picture of the whole, whereas quantitative studies may be more focused on measuring the parts. In the second situation, the grounded theory researcher is seeking to create a new theory from his or her observations, but the descriptive researcher may stop with stating "what is." Additionally, quantitative methods may be chosen when the research question is exact, and a more qualitative approach taken when the researchers are less specific in their question. For example, in studying patient response to transport stress, a quantitative design may be guided by hypotheses that list the specific variables to be measured and their anticipated relationship. In contrast, a research question to be addressed with qualitative methods will be less specific, such as what are the factors influencing the stress of transport for a cardiac patient. At the end of the qualita tive study, the researcher may be able to explicate a specific hypothesis to be tested in a subsequent study.

Another common method used to differentiate the two approaches is to state that quantitative studies generally use numbers and qualitative studies more commonly use descriptions. However, 
this explanation is not absolute. For example, a quantitative study that uses open-ended questions usually doesn't generate numerical responses.

This article will explore the qualitative method of grounded theory. ${ }^{4}$ As stated in the previous article, "the purpose of grounded theory is to generate explanatory theory that provides further understanding of social and psychologic phenomena. ${ }^{n}$ The example that will serve as the basis of this scenario is: what is the process by which a nurse develops expertise as an air medical crew member and modifies his or her practice to fit the transport environment? Nurses entering air transport previously have been identified as experts in such areas as trauma, critical care, or cardiac care. Authors like Benner ${ }^{5}$ have identified the process whereby expertise develops in registered nurses in inpatient units. However, the process of adapting that expertise to a much different environment (rather than patient population) is unknown.

Much of the discussion related to selecting an appropriate crew mix for transport focuses on the lack of experience in the prehospital setting for most nurses. This study is designed to provide insight into the process by which nurses adapt to the new environment and may increase understanding of the degree to which this change in practice venue may influence quality of care.

A qualitative approach was selected for this problem because the researcher does not already know what the important variables are in the situation. An open-ended approach will allow the theory to evolve from the data as they are collected.

\section{Ethical Considerations}

As with all research, the investigator first must obtain approval for the study. An application to the appropriate institution review board (IRB) for approval to use human subjects must be prepared for all research studies. The study must be approved by this ethics committee before any data can be collected or analyzed. The IRB, not the researcher, will decide whether the study qualifies for a waiver of review or consent or an expedited review. For further information on this process, see Part 5 of this series. ${ }^{6}$
The investigator also may need to obtain administrative approval from the management of the flight program from which the participants will be solicited. Administrative approval usually is necessary if the investigator wishes to approach potential participants while at work (eg, at a staff meeting). If volunteers will be solicited through personal contact, at a conference, or through advertisement, administrative approval may not be necessary.

The application for approval of a qualitative study may be shorter than that for a similar quantitative study because researchers often make design decisions as the study progresses. The exact questions to be asked may not be known at the outset, nor the specific number of participants to be accrued. The researcher may decide that participants need to be reinterviewed to clarify concepts or discuss topics revealed in later interviews. Although the application may be shorter, it should be no less rigorous. The investigator must explain areas in which decisions have not yet been made, why, and what options will be considered. Some IRBs may require the investigator to return for further approval as the study goes along and specific method decisions are made.

Just as the IRB needs to be kept apprised of the process to be used, so must the participants. As discussed in the previous article, the participant must be provided with enough information to allow him or her to provide informed consent to participate. The general process should be outlined for the participant, even if the specific questions are unknown. The researcher also should provide multiple opportunities for the participant to withdraw from the study once data collection has been initiated. In this example, the study may or may not be emotionally traumatizing for a given participant. However, the researcher should be alert to signs of a need for intervention if the participants encounter difficulty with the topics or emotions revealed during data collection.

\section{Participants}

For the study under discussion, the researcher has identified flight nurses as the subjects of interest. Because the amount of time needed for interviews is expected to be long, the researcher normally would select participants from the local geographic area. Unlike most quantitative studies, the exact number of participants generally is not determined at the outset of a study using grounded theory. Instead, the researcher uses a concept called saturation to determine when the appropriate sample size has been reached. Saturation is the process of collecting data until no new data are encountered. ${ }^{2}$

\section{Questions}

The purpose of grounded theory is to provide an understanding of a phenomena. In this study, the researcher is interested in role perceptions of nurses and paramedics. Open-ended questions are used to elicit the participants' beliefs. The researcher has identified only a few introductory questions to guide the interview. The first question is, "Tell me how you have adapted to practice in the prehospital setting." This question is sufficiently vague to allow the participant to move in whatever direction he or she desires, at least initially. The researcher in this study wishes to obtain data eventually on how participants see their role in patient care, what differences they perceive in this role in the prehospital setting, what methods they have used to adapt to this change, and what impact, if any, the change in environment has made on their performance.

\section{Procedures}

The researcher recruits participants from two local air transport programs. The researcher asks each program director for permission to speak to the team during a staff meeting. During the meeting, the purpose of the study and the anticipated procedures are explained. A sign-up sheet is posted to allow personnel to indicate their interest. In addition, the researcher leaves a business card with attendees so they have the option of contacting the researcher privately.

The researcher arranges a meeting with each volunteer individually in a convenient location. Participants are asked to arrange time for participation when they are not on duty. Although some types of data collection can occur with in- 
terruptions, interviews of the nature needed for grounded theory should be without interruption, if possible. The researcher attempts to see that the location for the interview is adequately cooled or heated. Comfortable seating should be available, as well as water or other beverages. The researcher arranges for the room to be quiet and adequately private. Because participants may share private feelings, the researcher must guarantee confidentiality of all data collected.

The researcher once again explains the study and obtains informed consent. After the first interview, this explanation may change as the researcher gains more knowledge of the participant and develops a stronger sense of the data being collected and how to best proceed in accumulating further data of value. The participant is reminded that he or she can withdraw from the study at any point.

All interviews are taped. The taping is explained to the participant and the recorder placed in an unobtrusive location that allows adequate sound pick up and permits the investigator to troubleshoot, change tapes, and perform other maintenance as needed.

The researcher starts the interview with the identified first question, "Tell me how you have adapted to practice in the prehospital setting," unless previous participant responses have indicated the need to modify the initial question. The participant is given enough time to formulate his or her thoughts and is not rushed. Although a set amount of time for the interview is established up front, the investigator asks permission to return if necessary to complete the initial interview or to obtain follow-up data.

As the participant begins to converse, the researcher listens attentively, providing encouragement for the participant to continue. The researcher may wish to keep notes relating to participant affect, posture, emotions, etc., during the interview. The researcher also may want to Inake short notes about themes or ideas emerging as the participant speaks.

As the participant's response begins to wind down, the researcher may pose a second question that serves as a follow-up to a theme or other topic identified in the initial conversation. For example, if the participant responded that the number of bystanders at a scene caused him or her increased stress and decreased efficiency when performing patient care procedures, the researcher may ask the subject to identify a specific situation in which he or she was required to perform a procedure in view of a crowd. Additionally, the researcher may ask the participant to discuss how he or she learned to adapt to such a stressful situation.

Unlike experimental methods or more quantitative research, the data collected during a grounded theory study do not need to be the same from participant to participant. Each interview is unique. The researcher should not think all participants need to be steered down the same path. Much of the richness of the data comes from following the path that the participant elects to pursue.

The researcher is constantly cognizant of time during the interview. Although the participant could appear to talk for hours, the researcher must respect the participant's time and end the interview as scheduled. However, the interview does not need to be unnecessarily drawn out just to use all the allotted time. When the participant appears to have run out of things to say, the researcher should thank him or her for the time and effort, request permission to contact him or her again if necessary, and make a graceful exit.

After the interview is over, the tape is marked carefully with participant, time, and date. Transcription of the tape and any written notes should occur as soon as possible so that data analysis can begin promptly, preferably before the next interview.

\section{Data Analysis}

When the investigator receives the transcripts from the first interview, he or she begins the process of analysis, which does not wait until data collection concludes. The researcher in this study attempts to identify themes that describe the role of the nurses and how they adapted to changes in their practice as required by the prehospital setting. In the above example, the first flight nurse identified the theme of stress caused by multiple onlookers. The researcher lists this concept as a potential theme, identi- fying the changes to which nurses must adapt as they shift their practice.

The process of analyzing data simultaneously with data collection is referred to as constant comparison. ${ }^{2}$ In grounded theory, the researcher uses emerging themes as a guide in subsequent interviews. During the next interview, the researcher uses a question to direct the participant toward the topic of prehospital stressors or the impact of bystanders on his or her practice as a way to validate a previously identified theme. If in a subsequent interview the researcher does not receive direct or indirect feedback that practicing in front of bystanders is stressful and affects performance, that theme does not need to be pursued.

Each subsequent interview is analyzed as soon as possible and the data compared with previous interviews. Themes will continue to emerge to guide the interviews. When interview themes become redundant with previous data, saturation has been obtained, and the interviews are concluded.

The purpose of data analysis in grounded theory is to derive a new theory to explain observed processes or be havior. In the example, the researcher is interested in how nurses adapt their practice to the prehospital environment while maintaining or reestablishing their expertise as a health care provider. During data analysis, the researcher not only identifies themes and categories but begins to provide a structure to the themes that will form the emerging theory. ${ }^{2}$ The goal of analysis is to provide a complete picture of the process of attaining expertise for flight nurses.

Unlike experimental research, grounded theory has no restriction on frequent reappraisal of the data or the data analysis. Occasionally the grounded theorist may find during data analysis that questions remain or that further data are necessary to fully understand an emerging theme. In this case, the researcher may elect to reinterview one or a group of participants. In the example, if the researcher did not identify until after data collection that the level of stress was more intense for critical care nurses than for trauma nurses, he or she may elect to question a group of subjects further to identify the cause of this difference. 


\section{Hypothetical Conclusions}

Conclusions from the grounded theory example are descriptive in nature. The hypothetical researcher concluded that three themes emerged from the data. First, the participants identified stress related to the newness of the situation as influencing the quality of their performance. This stressor was not unique to the transport environment and dissipated with time as the newness of the surroundings wore off.

Second, the theme of learning new skills emerged. The critical care nurses in particular realized that their unfamiliarity with immobilization devices caused a decrease in their level of expertise. The participants found that spending time using the equipment in the emergency department or classroom eased their stress and that their expertise rapidly returned because patient care goals were not that much different from the environment in which they had been working.

Finally, the theme of uncertainty emerged as the most difficult with which to deal. The participants identified several scenarios in which they had performed adequately but were uncertain whether they were providing the best care possible. This uncertainty affected the nurses' confidence and their self-perception of ex- pertise more than the quality of care actually provided to the patient.

\section{Summary}

Qualitative research is a method less commonly used by investigators to answer questions related to air transport. However, qualitative research is no less rigorous than more quantitative measures and, in many cases, may be a more appropriate approach. This article has provided a hypothetical example of a grounded theory study.

\section{References}

1. Thompson $\mathrm{CB}$, Walker BL. Basics of research (part 12): qualitative research. Air Med J 1998;17:65-70.

2. Polit DF, Hungler BP. Nursing research: principles and methods. Philadelphia: Lippincott; 1995.
3. Strauss A, Corbin J. Basics of qualitative research. Newbury Park: Sage Publications; 1990.

4. Glasser BG. Strauss AL. The discovery of grounded theory: strategies for qualitative research. Chicago: Aldine; 1967.

5. Benner P. From novice to expert. Menlo Park
(CA): Addison-Wesley Publishing; 1984.

6. Davis EA, Panacek EA, Thompson CB. Basics of research (part 5): ethics and human rights. Air Med J 1996;15:34-9. 